\title{
Evaluation of Mold and Mycotoxin Contaminations in Hybrid Hazelnuts Grown in Nebraska
}

\section{Yixiang $\mathrm{Xu}^{1 *}$, Andreia Bianchini ${ }^{2}$ and Milford A. Hanna ${ }^{3}$}

${ }^{1}$ Agricultural Research Station, Virginia State University, Petersburg, VA 23806, USA

${ }^{2}$ The Food Processing Center, University of Nebraska, Lincoln, NE 68583, USA

${ }^{3}$ Industrial Agricultural Products Center, University of Nebraska, Lincoln, NE 68583, USA

\begin{abstract}
Hybrid hazelnuts are a potential oilseed crop for food and value-added industrial applications, but they are vulnerable to mold contamination. Mold and mycotoxin contamination were investigated in three forms (whole nut, kernel, and ground meal) of Nebraska hybrid hazelnuts. The nut was the most contaminated form, followed by ground meal and kernel. Penicillium was the predominant genus isolated from all three forms, and Alternaria and Cladosporium also were prevalent. In spite of presence of several toxigenic molds, all tested samples were mycotoxin free.
\end{abstract}

Keywords: Hybrid hazelnut; Mold; Mycotoxin

\section{Introduction}

Hazelnuts (Corylus spp.), also known as filberts, are an important commercial crop in many countries. The United States is the third largest hazelnut producer in the world, behind Turkey and Italy. Commercial hazelnut cultivars in the US come from the European hazelnut (Corylus avellana) and are cultivated largely in Oregon, which produces three percent of the world's hazelnuts. European hazelnut varieties produce high quality, large nuts with thin shells. Producers in other areas of the US are interested in hazelnut cultivation, but climate conditions in many of these areas are unsuitable for European varieties. Further, European hazelnuts are not resistant to Eastern filbert blight, a hazelnut disease native to the eastern US that is uniformly fatal to the European hazelnut. In contrast, native North American species are cold-tolerant and disease resistant, but the nuts are small and of little commercial value. Commercial-quality hybrid hazelnut shrub cultivars, which combine the superior qualities of the European hazelnut with disease resistance and cold hardiness of the North American species, show great potential as an oilseed crop in the Upper Midwest [1] in part because they require relatively low inputs and can be produced on marginal lands.

A 9 ac hybrid hazelnut planting at Arbor Day Farm in Nebraska City, NE was established in 1996 and is currently one of the largest plantings of hybrid hazelnuts east of the Rocky Mountains. Arbor Day Farm has 5,200 genetically distinct hybrid hazelnut shrubs grown from open-pollinated seedlings derived from a breeding program at Badgersett Research Corporation, Canton, MN. A series of evaluations on the top 25 producing Nebraska hybrid hazelnuts suggested that a significant opportunity may exist to develop hazelnuts as an economically feasible, sustainable, and environmentally friendly oilseed crop for food, feed and industrial applications [2-5]. Like other oilseeds, however, hazelnuts are vulnerable to mold contamination during growth, harvesting, processing and storage stages, with potential for subsequent production of toxic secondary metabolites, known as mycotoxins [6].

Mold contamination in the hazelnut is prevalent, and mycotoxin contamination is a significant food safety issue due to serious adverse effects on human and animal health [7,8]. For example, aflatoxin (especially aflatoxin $\mathrm{B}_{1}$ ) is a potent carcinogenic and teratogenic mycotoxin with subacute and chronic effects, including liver cancer, chronic hepatitis, jaundice, hepatomegaly and cirrhosis [9]. Mycotoxin contamination also adversely impacts international trade of hazelnuts and stringent limits have been established for its control. The U.S. Food and Drug Administration set a maximum limit of $20 \mathrm{ng} / \mathrm{g}$ of total aflatoxin for human food [10], whereas the European Union has established threshold levels of $10 \mathrm{ng} / \mathrm{g}$ of total aflatoxin and $5 \mathrm{ng} / \mathrm{g}$ of alfatoxin $B_{1}$ for imported nuts intended for human consumption [11]. Ochratoxin A is not regulated in the United States, but the European Commission [12] has set regulatory limits of 0.5-10 ppb in different commodities. Hence, regarding food safety and security and international trade, it is important to characterize mold and mycotoxin contaminations of Nebraska grown hybrid hazelnuts to develop appropriate control strategies. The objectives of the present research were to identify and evaluate mold and mycotoxin contaminations in Nebraska grown hybrid hazelnut.

\section{Materials and Methods}

\section{Hazelnuts}

Hybrid hazelnuts were harvested by hand from the Arbor Day Farm in Nebraska City, NE. The nuts were mechanically de-hulled, sorted by size, and cracked. The processed nuts were placed in mesh bags and dried for several weeks in a well-ventilated area. After that, portions of whole nuts were shelled, and half of the kernels were ground into a meal to pass through a \# 40 sieve. The whole nuts, kernels, and ground meal were sealed in double sterile polyethylene bags to minimize the loss of water, and stored at $4^{\circ} \mathrm{C}$ until analyzed for mold and mycotoxin contaminations.

*Corresponding author: Yixiang $\mathrm{Xu}$, Agricultural Research Station, Virginia State University, Petersburg, VA 23806, USA, Tel: +1-804-524-5668; Fax: +1-804-5245186; E-mail: yixu@vsu.edu

Received August 17, 2011; Accepted September 24, 2011; Published September 26, 2011

Citation: Xu Y, Bianchini A, Hanna MA (2011) Evaluation of Mold and Mycotoxin Contaminations in Hybrid Hazelnuts Grown in Nebraska. J Food Process Technol 2:119. doi:10.4172/2157-7110.1000119

Copyright: (c) $2011 \mathrm{Xu} \mathrm{Y}$, et al. This is an open-access article distributed under the terms of the Creative Commons Attribution License, which permits unrestricted use, distribution, and reproduction in any medium, provided the original author and source are credited. 


\section{Total mold and yeast contamination}

Total mold and yeast counts of the samples were determined using a dilution plate method. About $25 \mathrm{~g}$ hazelnut samples (whole nuts, kernels, or ground meal) were suspended in $225 \mathrm{ml}$ of $0.1 \%$ peptone solution and homogenized. Homogenized samples were diluted with $0.1 \%$ peptone solution to concentrations of $10^{-2}, 10^{-3}, 10^{-4}$, and $10^{-5}$. Each dilution $(100 \mu \mathrm{l})$ was dispensed and spread onto sterile dichloran rose bengal chloramphenicol (DRBC) agar (VWR International, West Chester, PA) in Petri plates, followed by incubation at $25^{\circ} \mathrm{C}$ for 5 days. Total mold and yeast counts were estimated by back-calculation based on observed mold for each dilution and was expressed as the number of colony forming units (CFU) per gram in each sample.

\section{Identification of mold}

Following colony enumeration, molds spores were collected from observed colonies using a sterile loop and streaked on potato dextrose agar (PDA) plates. The plates were incubated at $25^{\circ} \mathrm{C}$ for 2 days. Mold spores were isolated a second time following the same protocol and incubated at $25^{\circ} \mathrm{C}$ for 5 days. Molds were grown for identification using spores from purified colonies collected using a sterile loop and dispersed in $0.1 \%$ aqueous agar. Three $10-\mu \mathrm{l}$ aliquots of sporecontaining agar were used to inoculate different growth media using a three-point inoculation pattern and were incubated for 7 days at $25^{\circ} \mathrm{C}$ ) (Figure 1). The growth media included Czapek yeast autolysate extract agar, malt extract agar, and creatine agar (VWR International, West Chester, PA). Molds were identified based on their macroscopic
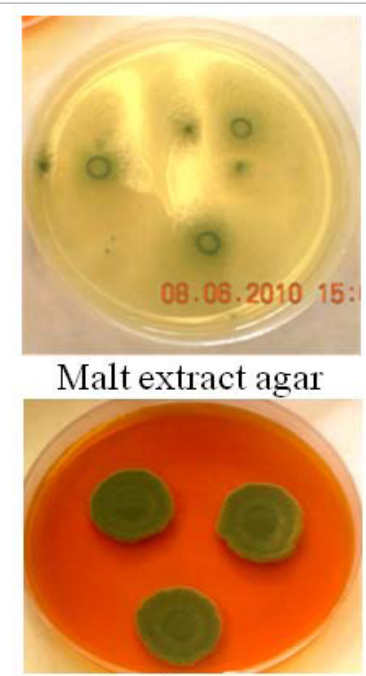

Creatine agar

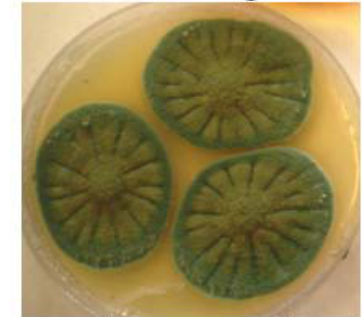

Czapek yeast autolysate extract agar

Figure 1: Three-point inoculation of mold on different growth media for identification after incubation for 7 days at $25^{\circ} \mathrm{C}$.

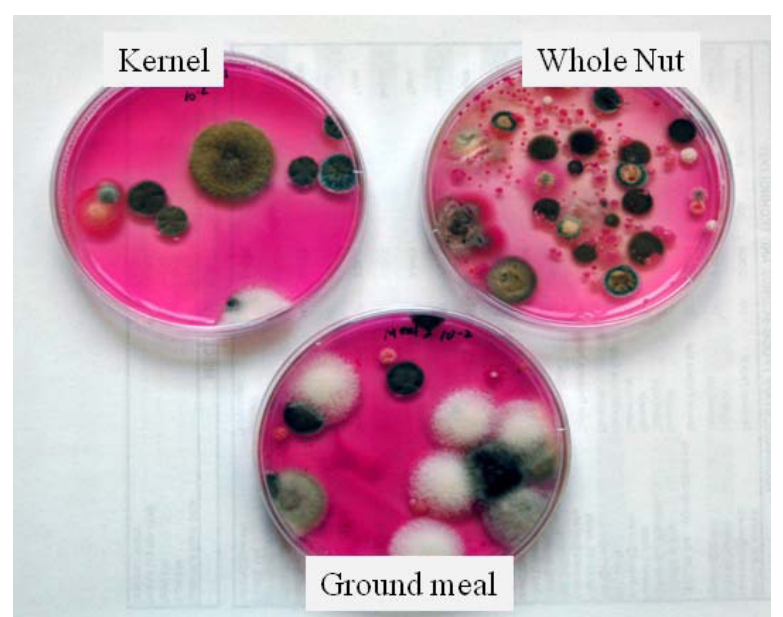

Figure 2: Total plate count for mold and yeast in the three forms (nut, kernel, and meal) of hazelnuts.

characteristics observed on each growth medium and their microscopic characteristics observed using a phase contrast microscope.

\section{Assessment of potential production of mycotoxins}

Mycotoxins produced by mold isolates, including aflatoxins $B_{1}, B_{2}$, $G_{1}$, and $G_{2}$, and ochratoxin, were assessed using a multi-toxin thin-layer chromatography (TLC) method [13]. Mold colonies were transferred into yeast extract sucrose (YES) broth and incubated for 7 days at $25^{\circ} \mathrm{C}$ for the production of secondary metabolites. Mycotoxin standard solutions (aflatoxin $B_{1}, B_{2}, G_{1}$ and $G_{2}$, and ochratoxin, $5 \mu \mathrm{l}$ ) and the samples in YES medium were spotted on TLC plates and allowed to migrate for a distance of $15 \mathrm{~cm}$ in a toluene-ethyl acetate-formic acid $(60+40+0.5)$ solvent system. The plates were inspected under longwave ultraviolet light. Samples with $\mathrm{R}_{\mathrm{f}}$ values that matched the standards were submitted for confirmation in a toluene-ethyl acetate-formic acid $(5+4+1)$ system and in a hexane-ethyl acetate-acetic acid $(18+3+1)$ system.

\section{Mycotoxin enzyme-linked immunosorbent assay (ELISA)}

The presence of ochratoxin A and aflatoxins in hazelnuts (whole nut, kernel, and ground meal) was tested using competitive direct enzyme-linked immunosorbent assay (Veratox CD-ELISA). The test results were read using an Awareness StatFax Microwell reader at $650 \mathrm{~nm}$ (Neogen Corporation, Lansing, MI). The detection limit and quantification range are $1 \mathrm{ppb}(\mathrm{ng} / \mathrm{g})$ and 2-25 ppb, respectively, for the Ochratoxin A test and 1.4 ppb (ng/g) and 5-50 ppb, respectively, for the Aflatoxin test. Extracts for the Ochratoxin A test were prepared using $25 \mathrm{~g}$ of sample mixed with $100 \mathrm{~mL}$ of $50 \%$ methanol/water solution, blended (Waring, Torington, CT) for 2 minutes, and filtered through Whatman \#1 filter paper. Extracts for the Aflatoxin test were prepared using $50 \mathrm{~g}$ of sample mixed with $250 \mathrm{~mL}$ of $70 \%$ methanol/water solution, blended for 3 minutes, and filtered through Whatman \#1 filter paper. Although not validated for any species of tree nut, the Ochratoxin A test [14] and the Aflatoxin test [15] can be used qualitatively to indicate the presence of these mycotoxins in nut samples.

\section{Results and Discussion}

\section{Total mold and yeast contamination}

Contamination was highest for the whole nut $\left(3.4 \times 10^{4} \mathrm{CFU} / \mathrm{g}\right)$, 


\begin{tabular}{|l|l|}
\hline Hazelnut & Mold genera \\
\hline Whole nut & Penicillium spp., Alternaria spp., Paecilomyces spp., Fusarium spp., and Cladosporium spp. \\
Kernel & Penicillium spp., Alternaria spp., Chrysonilia spp., and Cladosporium spp. \\
Ground meal & Penicillium spp., Alternaria spp., and Cladosporium spp. \\
\hline
\end{tabular}

Table 1: Mold genera present on the three types of hazelnuts examined.

was intermediate for ground meal $\left(1.2 \times 10^{3} \mathrm{CFU} / \mathrm{g}\right)$, and was lowest for the kernel $\left(7.0 \times 10^{2} \mathrm{CFU} / \mathrm{g}\right)$ (Figure 2). Higher counts for the whole nut were the result of greater mold contamination on the exterior surface of the shell. Mold contamination and growth begins in the field. The shell provides some natural defense against mold infestation, and it must be compromised for contamination of the kernel to occur. Vulnerability to contamination may increase during harvesting and storage due to improper handling that result in mechanical damage of the nuts. In addition, wind, insects, and poor storage environment including high moisture and temperature may also contribute to mold contamination $[16,17]$.

Kernel mold is reported to be the most serious defect that greatly shortens the shelf life of hazelnuts [18]. Quality changes, including dry matter loss, discoloration, flavor change, oil content decrease, and free fatty acid content increase, that accompanying mold contamination are a result of enzymatic degradation spoilage organisms on carbohydrates, fats, proteins, or other structural components of the nuts [19]. Strategies to control mold contamination include reduction of in-shell and nutmeat moisture contents as well as sanitation of the nuts with chlorine dips [20].

\section{Mold identification}

Penicillium spp. was the predominant genus isolated from all three hazelnut forms, though Alternaria spp. and Cladosporium spp.
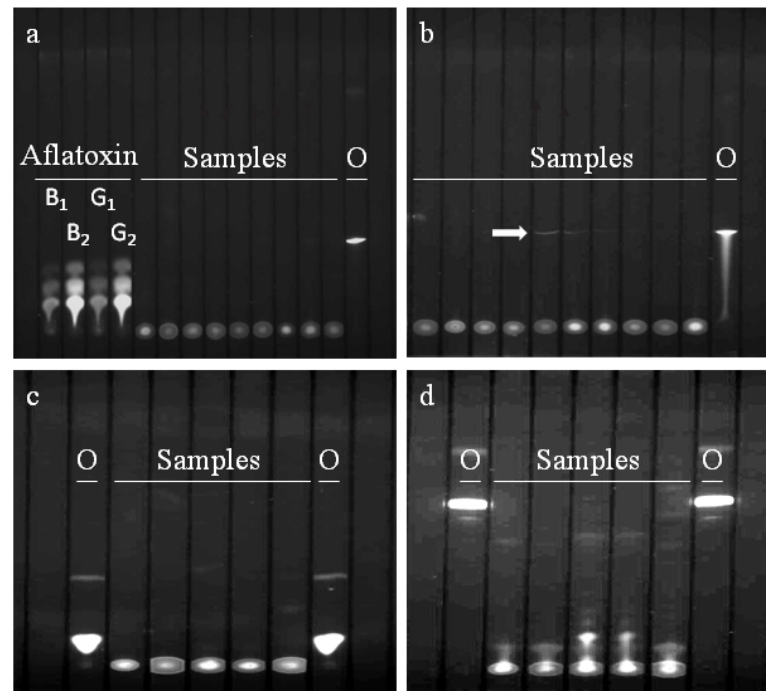

Figure 3: Mycotoxin screening of various mold isolates cultured inYES broth using a multi-toxin thin-layer chromatography. Chromatograms eluted in toluene-ethyl acetate-formic acid $(60+40+0.5)$ system (a) do not exhibit mycotoxins. Chromatograms eluted in toluene-ethyl acetate-formic acid $(60+40+0.5)$ system (b) show the possible presence of ochratoxin (O) (arrow) Chromatograms eluted in toluene-ethyl acetate-formic acid $(5+4+1)$ system (c) and in a hexane-ethyl acetate-acetic acid $(18+3+1)$ system (d) fail to confirm the presence of ochratoxin. also were prevalent (Table 1). Aspergillus spp. (especially A. flavus and $A$. parasiticus), the primary producers of aflatoxins [21,22], were not isolated in this study. Özdemir and Devres [19] found A. flavus in hazelnut kernels only when the shells are compromised by a minor hole or crack. Usually, hazelnuts are harvested from late October to early November and environmental conditions in Nebraska at that time may not be conducive to Aspergillus sporulation.

Pelant [23] summarized the predominant mold genera in hazelnuts grown in different areas. Prevalent mold genera in Turkish hazelnuts are Aspergillus fumigatus, A. flavus, A. versicolor, and Penicillium chrysogenum; while Aspergillus spp., Penicillium spp., Eurotium spp., and Cladosporium spp. are dominant in Egyptian hazelnuts. Aspergillus, Penicillium, Fusarium, along with Rhizopus stolonifer are dominant on hazelnut samples from German wholesale and retail markets. Saudia Arabian hazelnuts are spoiled by Aspergillus spp., Penicillium spp., Eurotium spp., Rhizopus stolonifer and Trichoderma hamatum. Aspergillus, Penicillium, and Fusarium are the most important toxigenic fungi that cause decay in food products [17].

\section{Mycotoxins production}

There was no correlation between presence of toxigenic molds and mycotoxin contamination. CD-ELISA assay results for ochratoxin $\mathrm{A}$ and aflatoxin were below the limits of detections indicating no significant production of these mycotoxins under the conditions tested even though several mold isolates belonged to toxigenic genera. Multitoxin thin-layer chromatography did not detect aflatoxin (Figure 3a) but showed the possibility of ochratoxin production by some of the mold isolates (Figure 3b). However, this was not confirmed in two other solvent systems (Figure $3 \mathrm{c}$ and $3 \mathrm{~d}$ ). These results are in agreement with previous reports that hazelnuts for human consumption are rarely contaminated with mycotoxins, which is attributed to low moisture levels present in these products [24,25]. However, other studies have reported high incidences of aflatoxin contamination, some exceeding European Union and FDA limits [9,21,22].

The presence of toxigenic molds does not automatically mean the presence of mycotoxins. Instead, it only indicates a potential risk for toxin formation. On the other hand, the absence of any mycotoxinproducing species does not preclude certain levels of mycotoxins in the samples as the toxins might accumulate in the raw materials before the destruction of molds during the production process, since they can persist long after the molds have disappeared [26,27].

\section{Conclusion}

Contamination of hazelnuts with molds is of concern because the potential for quality deterioration of the product and for mycotoxin production, respiratory complications, and other health problems that can affect processors. Although no mycotoxin was produced by any of the molds isolated from three forms of hazelnut at the time of analysis, it does not imply that the toxin could not be produced under different conditions, i.e. in the hazelnuts during storage if favorable 
Citation: Xu Y, Bianchini A, Hanna MA (2011) Evaluation of Mold and Mycotoxin Contaminations in Hybrid Hazelnuts Grown in Nebraska. J Food Process Technol 2:119. doi:10.4172/2157-7110.1000119

environmental conditions for fungal development and toxin formation were present. Preventative strategies, including minimization of shell damage, appropriate and adequate storage conditions (e.g. storage in high air-permeable sacks, cool and dry condition, assisted drying), are recommended to minimize or prevent toxigenic mold growth and mycotoxin production.

\section{Acknowledgement}

The authors are grateful to Hui Gao for his assistance in preparing and analyzing the samples, and Dr. Edward Sismour for editorial assistance. This research was supported, in part, by funds provided through the USDA Hatch Act, USDA Evans-Allen, and the Nebraska Department of Agriculture Specialty Crop Block Grant Programs. The article is a contribution of a joint effort between Virginia State University Agricultural Research Station and the University of NebraskaLincoln.

\section{References}

1. Hammond $E$ (2006) Identifying superior hybrid hazelnut plants in southeast Nebraska. Masters thesis. 60 Lincoln, University of Nebraska.

2. Xu YX, Hanna MA, Josiah SJ (2007) Hybrid hazelnut oil characteristics and its potential oleochemcial application. Industrial Crops and Products 26: 69-76.

3. Xu YX, Hanna MA (2009) Synthesis and characterization of hazelnut oil-based biodiesel. Industrial Crops and Products 29: 473-479.

4. Xu YX, Hanna MA (2010) Evaluation of Nebraska hybrid hazelnuts: nut and kernel characteristics, proximate, oil and protein properties. Industrial Crops and Products 31: 84-91.

5. Xu YX, Hanna MA (2010) Nutritional quality and oxidative stability of oil extracted from hybrid hazelnuts. International Journal of Food Science and Technology 45: 2329-2336.

6. Gürses M (2006) Mycoflora and aflatoxin content of hazelnuts, walnuts, peanuts, almonds and roasted chickpeas (Leblebi) sold in Turkey. International Journal of Food Properties 9:395-399.

7. Sanchis V, Quilez ML, Viladrich R, Vinas I, Canela R (1988) Hazelnuts as possible substrate for aflatoxin production. Jounal of Food Protection 51: 289292.

8. Heperkan D (2006) The importance of mycotoxin and a brief history of mycotoxin studies in Turkey. The Bulletin of the Istanbul Technical University 54:18-27.

9. Ozay G, Seyhan F, Yilmaz A, Whitaker TB, Slate AB, et al. (2006) Sampling hazelnuts for aflatoxin: uncertainty associated with sampling, sample preparation, and analysis. J AOAC Int 89: 1004-1011.

10. Food and Drug Administration, 2000. Guidance for Industry: Action Levels for Poisonous or Deleterious Substances in Human Food and Animal Feed.

11. Commission of the European Community, 2010. Commission Directive 165/2010 of 26 February 2010 amending regulation (EC) 1881/2006 setting maximum levels for certain contaminants in foodstuffs as regards aflatoxins. Official Journal of European Community Legislation, 27.2.2010 p. 50/11.

12. Commission of the European Community, 2006. Commission Directive 1881/2006 of 19 December 2006 setting maximum levels for certain contaminants in foodstuffs. Official Journal of European Community Legislation, L364, 20.12.2006 p. 5 .

13. Valentes Soares LM, Rodriguez-Amaya DB (1989) Survey of aflatoxins, ochratoxin A, zearalenone, and sterigmatocystin in some Brazilian foods by using multi-toxin thin-layer chromatographic method. J Assoc Off Anal Chem 72: $22-26$.

14. Neogen Corporation. Veratox ${ }^{\circledR}$ For Ochratoxin. http://www.neogen.com/ FoodSafety/pdf/Prodlnfo/Page_V-Ochra.pdf. Accessed on 8/15/2011.

15. Neogen Corporation. Veratox® For Aflatoxin. http://www.neogen.com/ FoodSafety/pdf/Prodlnfo/Page_V-Afla.pdf. Accessed on 8/15/2011.

16. Gürses M, Erdoğan A, Türkoğlu H, Sert S (2001) The effects of storage period and relative humidity on Tombul type hazelnut produced in Turkey. Pakistan Journal of Biological Science 4: 858-860.
17. Khosravi AR, Shokri $H$, Ziglari $T$ (2007) Evaluation of fungal flora in some important nut products (pistachio, peanut, hazelnut and almond) in Tehran Iran. Pakistan Journal of Nutrition 6: 460-462.

18. Mehlenbacher SA, Smith DC, Brenner LK (1993) Variance components and heritability of nut and kernel defects in hazelnut. Plant Breeding 110: 144-152.

19. Özdemir M, Devres O (1999) Turkish hazelnuts: properties and effect of microbiological and chemical changes on quality. Food Reviews International 15: 309-333.

20. K. Gross, M.Saltveit, C.Y. Wang , Maness NO (2005) Hazelnut: postharvest quality maintenance guidelines: The commercial storage of fruits, vegetables, and florist and nursery stocks. USDA, ARS Agriculture Handbook No. 66.

21. Bacaloni A, Cavaliere C, Cucci F, Foglia P, Samperi R, et al. (2008) Determination of aflatoxins in hazelnuts by various sample preparation methods and liquid chromatography-tandem mass spectrometry. J Chromatogr A. 1179: 182-189.

22. Gürses M (2005) Mycoflora and aflatoxin content of hazelnuts, walnuts, peanuts, almonds and roasted chickpeas (leblebi) sold in Turkey. International of Journal Food Properties 9: 395-399.

23. Pelant K (2002) Characterization of fungi with molecular methods. Diploma thesis at Karl-Franzens-Universität Graz, Institut für Botanik.

24. Jiménez M, Mateo R, Querol A, Huerta T, Hernández E (1991) Mycotoxin and mycotoxigenic moulds in nuts and sunflower seeds for human consumption. Mycopathologia 115: 121-127.

25. Abdel-Gawad K, Zohri AA (1993) Fungal flora and mycotoxins of six kinds of nut seeds for human consumption in Saudi Arabia. Mycopathologia 124: 55-64

26. Bullermall LB (1986) Mycotoxins and food safety. Food Technology 40: 59-66.

27. Halt M, Klapec T, Šubarić D, Macura M, Bačani S (2004) Fungal contamination of cookies and the raw materials for their production in Croatia. Czech Journal of Food Science 22: 95-98. 